\title{
Study of Congenital Malformations in Fetal and Early Neonatal Autopsies
}

\author{
Pradnya Pandurang Kale*, Sujata R. Kanetkar, Dhirajkumar B. Shukla, Atul Bhanudas Hulwan \\ Pramod Borade and Nikita Vinod Vohra
}

Department of Pathology, Krishna Institute of Medical Sciences, Karad, Satara, Maharashtra, India

\begin{abstract}
Background: Antenatal care in India is rising due to improvement in awareness; still few congenital malformations can be missed in routine check-ups. One lost baby due to birth defects raises questions like; did the malformation led to death, what was the exact nature of malformation, will it recur in next pregnancy and are there any preventive measures? Few congenital malformations can be diagnosed prenatally with ultrasonography techniques, various maternal serum assays, confirmation relies on actual examination of the fetus or neonate. These techniques cannot identify large proportion of congenital malformations for which perinatal autopsy remains the gold standard investigation. The result of a perinatal autopsy may have broad impact, in that obstetrical, fetal, maternal, paternal, and familial conditions may be uncovered.
\end{abstract}

Methods: The descriptive analytical study was carried out in Department of Pathology of a tertiary care hospital from June 2014 to May 2016 for detection of congenital malformations in fetal and early neonatal autopsies in 5 years.

Conclusion: Despite advances in imaging such as antenatal ultrasonography and serology, perinatal autopsy is superior and continues to play an important role in diagnosing congenital malformations. The findings of autopsy are not only of theoretical importance but also of practical significance to clinicians in the form of estimating the risk of recurrence and in genetic counseling.

Keywords: Congenital Malformations, Perinatal Autopsy, malformation Syndromes.

\section{Introduction}

Congenital means "Present since birth". Congenital malformation is a physical, metabolic or anatomic defect which is apparent before birth, at birth or detected during the first year of life. Congenital malformations are a major cause of fetal and neonatal deaths as well as disability cases worldwide. The varying pattern and prevalence of congenital malformations over time or geographical location are known. It reflects differing methods of detection and recording.

There are also true differences in frequency due to the complex interaction of known and unknown genetic and environmental factors including socio-cultural, racial, and ethnic variables. For quite some time, congenital malformations have been reported to be a major cause of mortality and morbidity in children in the developed countries. ${ }^{[1-6]}$

In the recent years, congenital disorders are becoming to be public health issue in developing countries, due to an epidemiological transition, which involves significant decline in infant mortality rates due to reduction of infections and malnutrition and relative increase of morbidity and mortality due to congenital malformations. ${ }^{[7-14]}$ Antenatal investigations, such as ultrasonography
(USG), maternal serum enzyme hormone assays cannot determine significant number of congenital malformations, for which autopsies are must. ${ }^{[15]}$

Fetal and early neonatal autopsy in cases of congenital malformations not only confirms but also provides additional information and is helpful in counseling the parents regarding prevention of similar congenital malformations in future pregnancies. The variety and complexity of congenital anomalies found in perinatal and fetal autopsies are endless, and the Pathologist must be prepared to spend the necessary time demonstrating these anomalies. The majority of the malformations found in this perinatal population are lethal. It is essential to have basic epidemiological information on congenital malformation for planning health care services. This study is therefore undertaken to ascertain various congenital malformations and to classify those according to organ system involved and measure the utility of autopsy in final diagnosis.

\section{Materials and Method}

This descriptive analytical study was carried out in Department of Pathology of a tertiary care hospital from June 2014 to May 2016 for detection of congenital malformations in fetal and early neonatal autopsies. 
Consent for the autopsy was taken from the parents/ relatives on a proforma prepared according to guidelines provided by the Institutional Ethics Committee. Perinatal autopsies done in Department of Pathology between the period of June 2014 to May 2016 were studied and analysed. Also, perinatal autopsy specimens from June 2011 to May 2014 preserved in the department with medical records were studied and included in the study. Thus, data included in the present study is of 5 years - June 2011 to May 2016.

\section{Inclusion criteria}

- Autopsies of fetuses with gestational age above 20 weeks of intra uterine life and birth weight greater than 350 gms.

- Autopsies of neonates within 7 days of post natal life.

\section{Exclusion criteria:}

- Autopsies of fetuses of gestational age $<20$ weeks,

- Autopsies of neonates above 7 days

- Autolysed dead fetuses or neonates

Relevant clinical data (maternal history and antenatal investigations) was collected from the case sheets. During autopsy procedure, photographs were taken for unusual gross findings. Post mortem radiographs of abnormal features were taken whenever required. For each fetus or neonate, morphometric examination was done.

Autopsies were performed by the standard technique adopted by EDITH. L. POTTER. ${ }^{[16]}$

Sections from each organ were submitted for histopathological examination. Following routine tissue processing, paraffin embedding, section cutting, staining was performed by routine Haematoxylin and Eosin stains. Clinical data and the pathological findings were recorded in proforma. Autopsy findings were compared with antenatal ultrasound findings. Microphotographs were taken in cases with congenital malformations diagnosed on histopathological study (microscopy).

Malformations were classified into organ systems according to World Health Organization (WHO) recommendations, International Statistical Classification of Diseases and Related Health Problems 10th Revision (ICD-10) Version for 2010, Chapter XVII (Q00-Q99) Congenital Malformations, Deformations and Chromosomal abnormalities. ${ }^{[17]}$

\section{Results}

During this period, total 223 perinatal autopsies were done and 57 autopsies showed various congenital malformations comprising $25.56 \%$ of perinatal autopsies. These 57 perinatal autopsies with congenital malformations were further analysed.

Out of total 57 cases 54 were fetal and 3 were early neonatal autopsies. There was slight male preponderance (52.63\%) observed in the present study. Ambiguous genitalia was observed in 3 fetuses.

Maximum fetuses $(63.15 \%)$ were from gestational age group of 20-24 weeks. Among all the fetuses with congenital malformations, $71.92 \%$ were having low birth weight (ranging from 350-1000 grams) for the gestational age.

Maximum number of fetuses 39 (68.42\%) were born to mothers in age group of $20-24$ years and $50.87 \%$ mothers were primipara. One of the three neonates was a case of Down's syndrome and born to a mother of age 36 years with bad obstetrics history. Bad obstetric history was noted in 14 mothers, out of those 2 showed high titre for TORCH complex. History of consanguinity was present in 4 mothers $(7.02 \%)$ out of all congenitally malformed cases.(Table No.1)

There were significant additional findings observed in 31 autopsies when compared with antenatal ultrasonographic findings. Antenatal ultrasonographic diagnosis was totally changed in 3 cases after final autopsy diagnosis. (Table No. 2) In 13 perinatal autopsies, multiple organ systems were involved by congenital malformations suggesting insult during common embryological period of development. (Table No. 3) A case of acardiacacephalic fetus was diagnosed on morphological examination (Fig. No. 1) In the present study, the commonest system affected by congenital malformations was musculoskeletal system (19.30\%).Varieties of malformations involving musculoskeletal system were Omphalocele, diaphragmatic hernia and Congenital Talipes Equinovarus.

Central nervous system was involved in 9 cases of congenital malformations. Neural tube defects were the commonest subgroup. Rare case of Holoprocencephaly was also diagnosed. ( Fig. No. 2) Various other major systems affected by congenital malformations were cardiovascular system (12.28\%); renal system (7.02\%), respiratory system (3.51\%). Polycystic kidneys were noted in a case grossly, and microscopically confirmed. (Fig. No. 3) Various rare syndromes were identified in the study viz. Pentalogy of Cantrell (Fig. No.4), Sirenomelia (Fig. No.5), Limb Body Wall Complex; one case of each.

Down's syndrome and Edward's syndrome were 2 chromosomal abnormalities diagnosed morphologically in the study, confirmed on cytogenetic studies. 
Table 1: Maternal Factors seen in malformed fetuses\& neonates.

\begin{tabular}{|l|c|c|}
\hline \multicolumn{1}{|c|}{ Maternal Age in years } & Number (out of 57) \\
\hline$<20$ & & 00 \\
\hline $20-24$ & 39 & 68.42 \\
\hline $25-29$ & 14 & 24.56 \\
\hline$>30$ & 4 & 7.02 \\
\hline Parity & & 50.87 \\
\hline Primipara & 29 & 47.37 \\
\hline Multipara & 27 & 1.76 \\
\hline Grand multipara & 01 & \\
\hline Consanguinity & & 7.02 \\
\hline Yes & 04 & 92.98 \\
\hline No & 53 & \\
\hline H/o Previous Abortion & & \\
\hline Yes & 14 & 24.56 \\
\hline No & 43 & 75.44 \\
\hline
\end{tabular}

Table 2: Correlation of Antenatal USG findings with Autopsy findings.

\begin{tabular}{|l|l|l|}
\hline Correlation of USG findings and autopsy findings & Cases & Percentage (\%) \\
\hline USG findings confirmed on autopsy & $\mathbf{5 4}$ & 94.74 \\
- No change in diagnosis $\quad$ Additional findings noted in the autopsy & 27 & 47.37 \\
\hline Changes in Diagnosis & 27 & 47.37 \\
\hline Total & 03 & 5.26 \\
\hline
\end{tabular}

Table 3: System wise distribution of Various Congenital Malformations in the Study

\begin{tabular}{|l|c|c|}
\hline System affected in congenital malformations & Number of cases & Percentage (\%) \\
\hline Central Nervous system & 09 & 02 \\
Spina Bifida & 01 \\
Spina Bifida with single umbilical artery & 01 \\
Spina Bifida, anencephaly, Craniofacial Rashischisis & 01 \\
Spina Bifida, Hydrocephalus & 01 \\
Anencephaly & 01 \\
CraniospinalRashischisis & 01 \\
Holoprocencephaly & 01 \\
Meningomyelocele, Hydrocephalus & 12 \\
\hline Musculoskeletal system & 03 \\
Diaphragmatic hernia & 01 \\
Omphalocele & 02 \\
CTEV & 01 \\
CTEV, Rocker Bottom foot & 02 \\
Radial Ray anomaly & 01 \\
Limb deformity & 01 \\
Hypoplastic Nasal Bone & 01 \\
Arthropogyrosis & 01 \\
\hline
\end{tabular}




\begin{tabular}{|c|c|c|}
\hline System affected in congenital malformations & Number of cases & Percentage (\%) \\
\hline $\begin{array}{l}\text { Cardiovascular system } \\
\text { Atrial Septal Defect alone } \\
\text { Atrial Septal Defect, Ventricular Septal defect } \\
\text { Atrial Septal Defect, Ventriculomegaly } \\
\text { Ventricular Septal Defect alone } \\
\text { Ventricular Septal Defect, Transposition of great vessels } \\
\text { Abnormal aorto-pulmonary communication } \\
\text { Hypoplastic heart syndrome }\end{array}$ & $\begin{array}{l}07 \\
01 \\
01 \\
01 \\
01 \\
01 \\
01 \\
01\end{array}$ & 12.28 \\
\hline $\begin{array}{l}\text { Urinary system } \\
\text { Renal Agenesis } \\
\text { Polycystic kidneys } \\
\text { Polycystic kidneys } \\
\text { Dysplastic kidneys }\end{array}$ & $\begin{array}{l}04 \\
01 \\
01 \\
01 \\
01\end{array}$ & 7.02 \\
\hline $\begin{array}{l}\text { Respiratory system } \\
\text { Congenital Cystic AdenomatoidMalformation } \\
\text { Bilateral Hypoplastic lungs }\end{array}$ & $\begin{array}{l}02 \\
01 \\
01\end{array}$ & 3.51 \\
\hline $\begin{array}{l}\text { Eye, Ear, Face \& Neck system } \\
\text { Bilateral Cataract }\end{array}$ & 01 & 1.75 \\
\hline $\begin{array}{l}\text { Lymphatic system } \\
\text { Cystic Hygroma }\end{array}$ & 01 & 1.75 \\
\hline $\begin{array}{l}\text { Multiple systems } \\
\text { Spina Bifida- Lumbar level, Low set ears, B/L CTEV } \\
\text { Persistent cloaca, Bladder Obstruction syndrome, Limb deformity } \\
\text { Right renal Agenesis, Persistent Cloaca, Bladder Obstruction syndrome, B/L } \\
\text { CTEV } \\
\text { Ambiguous genitalia, Omphalocele, Imperforate Anus, Kyphosis, B/L lower limb } \\
\text { deformity, Vertebral deformity } \\
\text { Spina Bifida with Scoliosis, Occiputo-cervical Cystic Hygroma } \\
\text { Corpus Callosal Agenesis, Spina Bifida, Diaphragmatic hernia, B/L hypoplastic } \\
\text { lungs, Dysmorphic facial features } \\
\text { Spina bifida occulta, B/L cataract } \\
\text { Right Testis agenesis, Undescended left testis, Limb deformity, Dysmorphic face } \\
\text { B/L hypoplastic lungs, Fallot's tetralogy, Diaphragmatic hernia } \\
\text { Acephalicacardiacfetus } \\
\text { B/L Hypoplastic lungs, B/L Hypoplastic kidneys, Potter' s facies } \\
\text { Hydrocephalus, Imperforate anus } \\
\text { Cleft Lip, Cleft Palate, Bifid tongue }\end{array}$ & $\begin{array}{l}13 \\
01 \\
01 \\
01 \\
01 \\
01 \\
01 \\
01 \\
01 \\
01 \\
01 \\
01 \\
01 \\
01\end{array}$ & 22.81 \\
\hline $\begin{array}{l}\text { Syndromes identified } \\
\text { Down's syndrome } \\
\text { Edward's syndrome } \\
\text { VACTERAL- H syndrome } \\
\text { Limb body wall complex } \\
\text { Sirenomelia } \\
\text { Pentalogy of Cantrell } \\
\text { Tethered cord syndrome } \\
\text { Potter's syndrome }\end{array}$ & $\begin{array}{l}08 \\
01 \\
01 \\
01 \\
01 \\
01 \\
01 \\
01 \\
01\end{array}$ & 14.04 \\
\hline Total & 57 & 100 \\
\hline
\end{tabular}




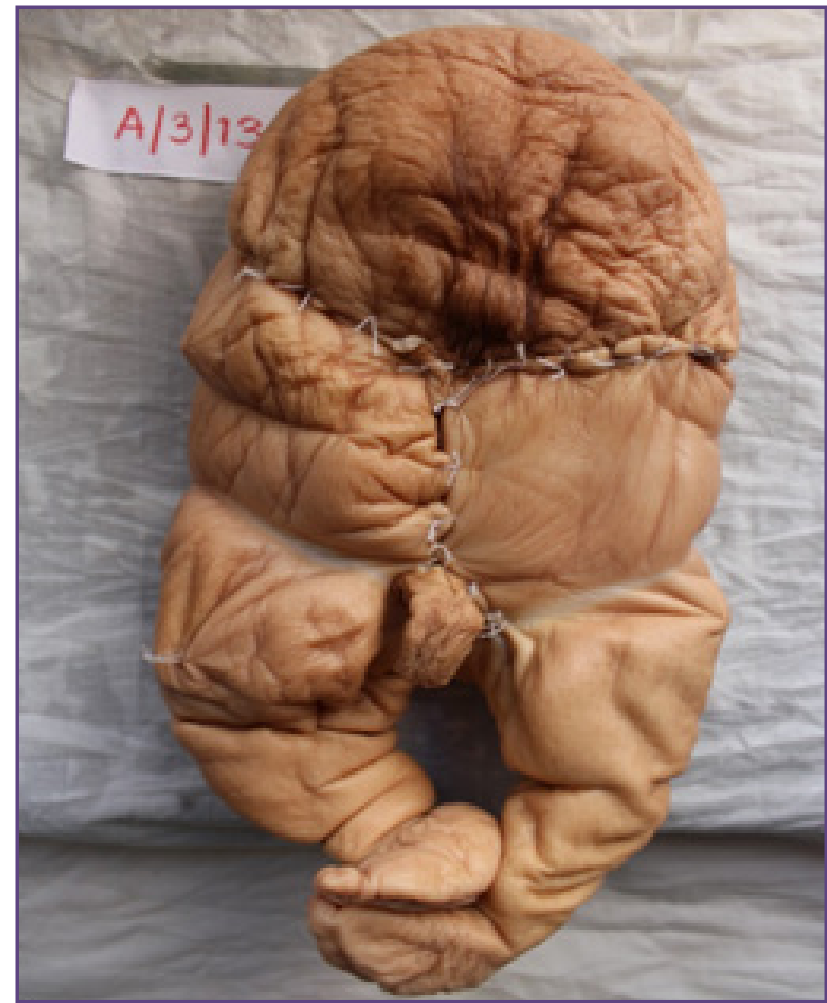

Fig.1: Photograph showing acardicacephalicfetus.

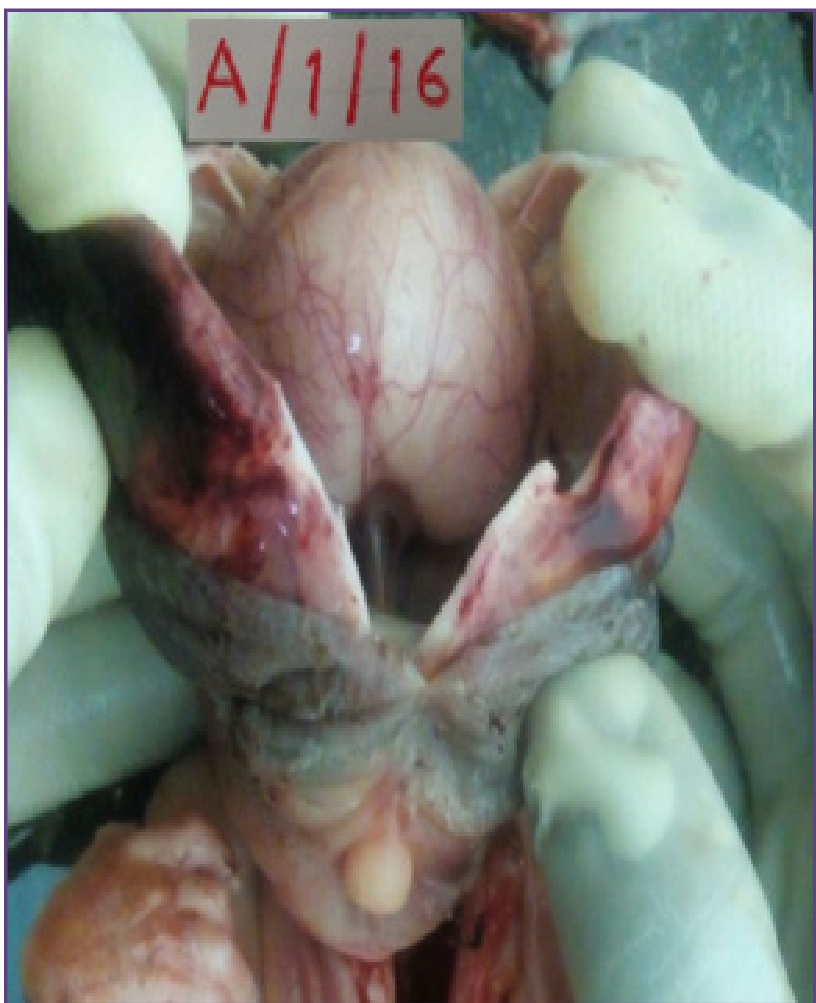

Fig. 2: Cut open cranial vault showing Holoprocencephaly

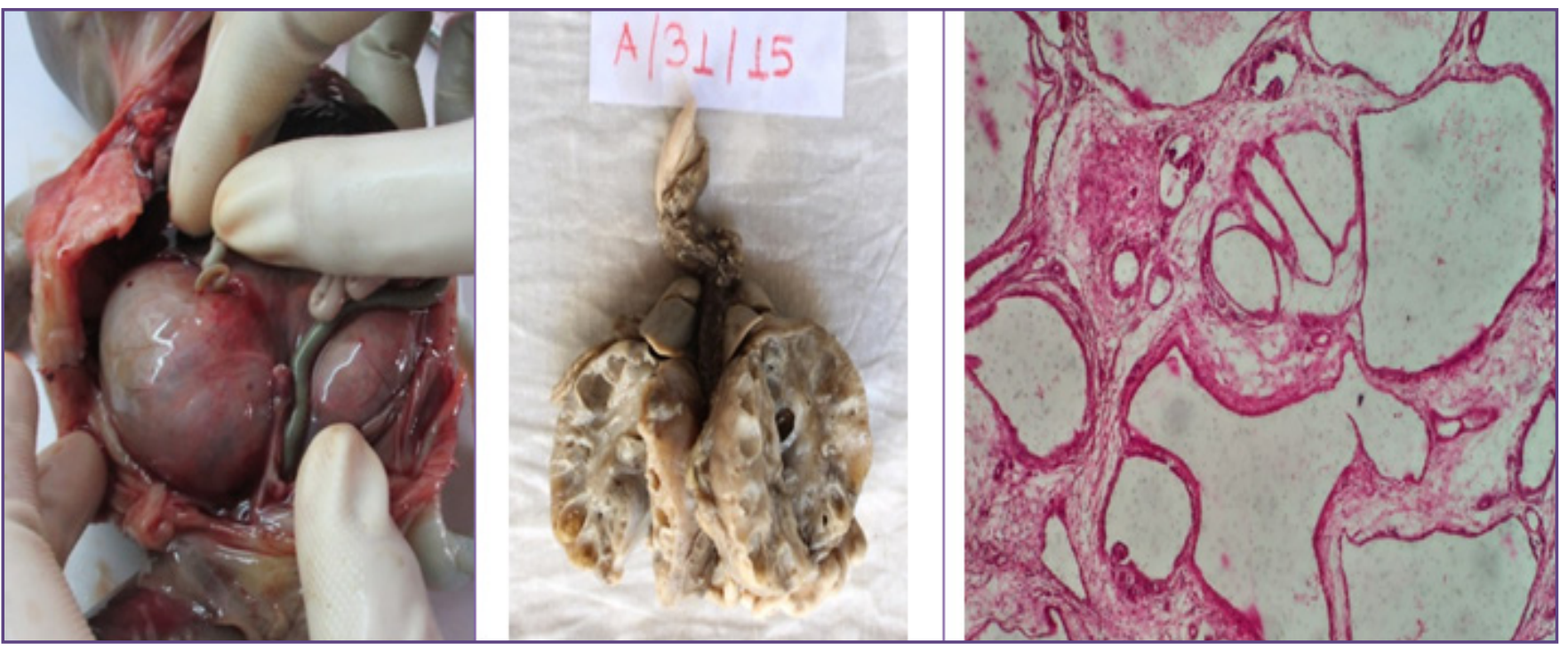

Fig. 3: Photographs showing in situ examination of fetus with enlarged kidneys, cut section of Polycystic kidneys and photomicrograph showing multiple dilated cysts in kidney of fetus having grossly polycystic kidneys (H \& E,100 x). 


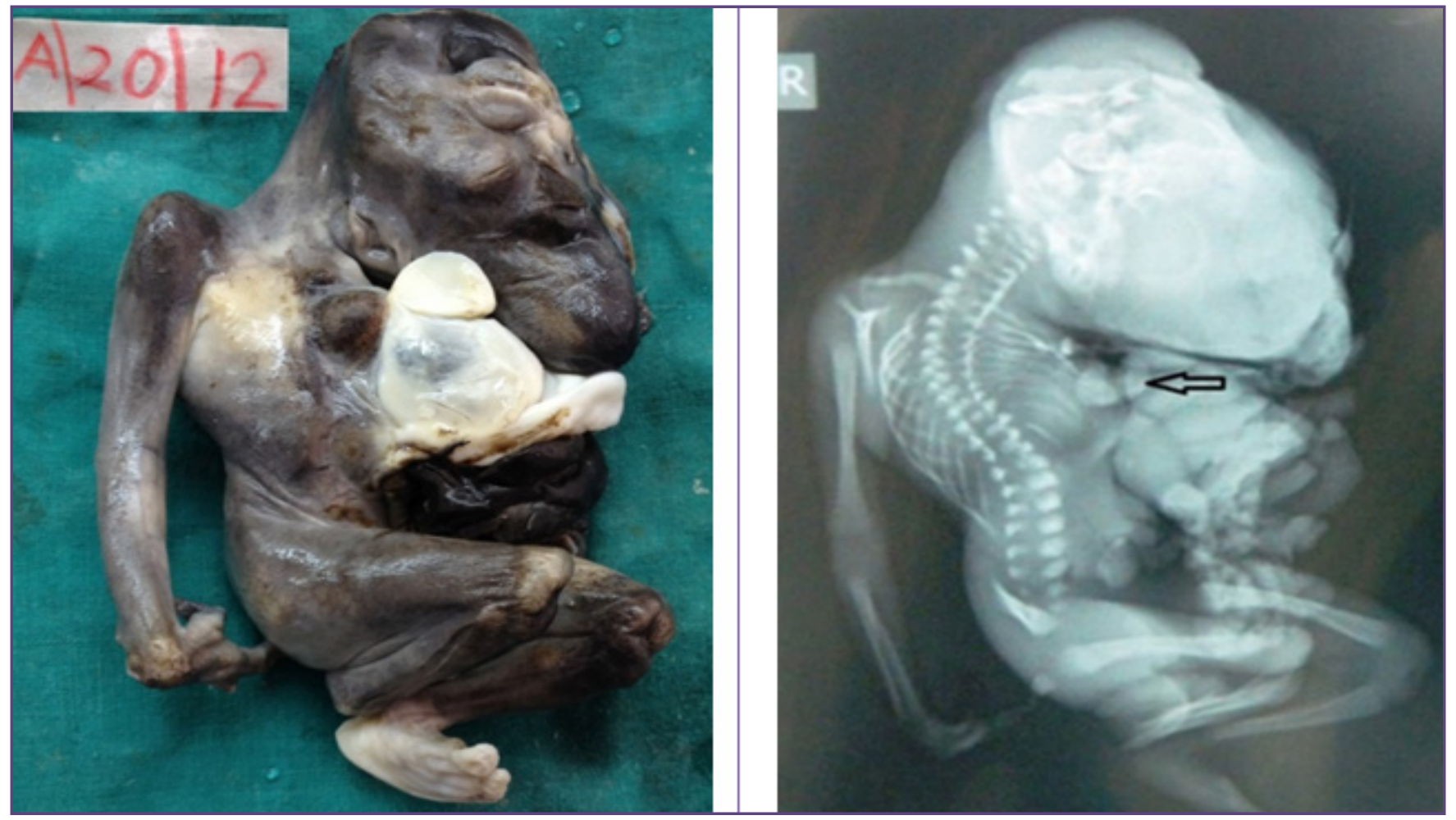

Fig. 4 : Photograph and Postmortem Radiogram showing malformed fetus with thoraco-abdominal wall defect (Omphalocele), ectopiacordis (arrow), multiple limb and facial deformities, spinal defects in a case of Pentalogy of Cantrell.

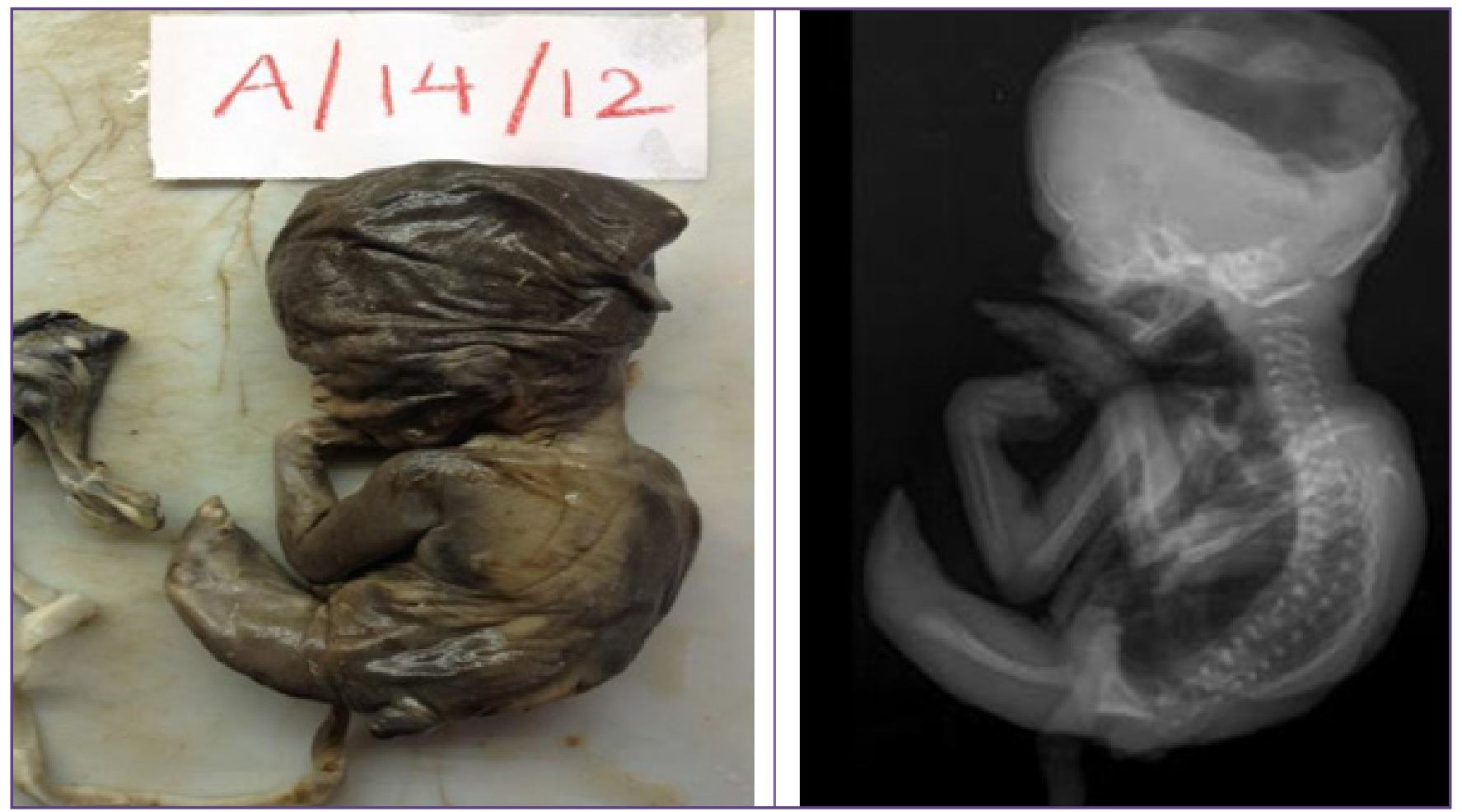

Fig. 5 : Photograph and Postmortem Radiogram showing Kyphoscoliosis, Single Femur, Absent Tibia, Fibula in a case of Sirenomelia. 


\section{Discussion}

The awareness regarding fetal and neonatal (perinatal) mortality and its preventable causes is increasing. It has led to increase in finding the preventable causes of death in perinatal period. Few of the malformations are preventable by acquiring few simple measures such as intake of folic acid during the child bearing age.

As congenital malformations are known to recur, physicians are interested in finding the chances of recurrence. The presence of congenital malformation in baby has profound emotional effect on mother. In additional to that loosing such baby gives not only blame but also physical and mental burden to mother.

During the most sensitive period of embryogenesis i.e. the $3 \mathrm{rd}-8$ th weeks of gestation, along with genetic factors other factors like environmental, teratogenic and infectious agents play important role for the causation of malformations. Autopsy plays role in identification and confirmation of malformations.

Out of 223 perinatal autopsies performed 57 (25.56\%) had congenital malformations, similar incidence was noted by Mohan et al 2004 (38.7\%). ${ }^{[18]}$ However, Kapoor et al 2013 (69\%) and Puri et al 2009 (63\%) noted higher incidence in their study.

Fetal Factors: On comparing the sex ratio, the congenital malformations were slightly more in males $(52.63 \%)$ with male to female ratio being 1.25:1. Pattanaik $\mathrm{T}$ et al have found the incidence to be more in males (56\%) with ratio of 1.37:1. ${ }^{[19]}$ But many studies have reported almost same incidence in males and females. ${ }^{[20]}$ In the present study, there were 3 cases $(5.26 \%)$ where sex of the fetus was ambiguous. Similar finding was noted by study done by Hakverdi S et al (6.25\%). ${ }^{[21]}$

Gestational age of most of the fetuses with congenital malformation ranged from 20-24 weeks $(63.15 \%)$. This could be attributed to therapeutic termination done in this period after detecting malformation on ultrasonography. The association of low birth weight for gestational age and malformations has been well documented. ${ }^{[20,22]}$ Similar to other studies; fetuses with congenital malformations had the weight in the range of 350-1000 grams (low for gestational age) in the present study. ${ }^{[20,22,23]}$

Maternal Factors: Maternal age is an important parameter in the birth of congenitally malformed fetuses. ${ }^{[18]}$ Maximum number of fetuses 39 (68.42\%) were born to mothers in age group of 20-24 years. This finding was similar with study done by Subhashini et al in 2015(41.8\%)

${ }^{[24]}$ and Kapoor et al $(60 \%) .{ }^{[18]}$

Bad Obstetric history, with one or more than one abortions; was present in 14 mothers $(24.56 \%)$. Similar results were noted by Subhashini et al with $33.4 \% .^{[24]}$

Among the malformed fetuses or neonates, $50.87 \%$ were born to primigravida. Similar finding was seen by Kapoor $\mathrm{K}$ et al $(50 \%){ }^{[18]}$ (Subhashini et al $(40.1 \%),{ }^{[24]}$ and Parmar A et al $(42 \%)^{[20]}$ Consanguinity has been described as an important factor contributing to increased congenital malformations. In this study, the consanguinity was noted in $7.02 \%$ cases, this is comparable to study done by Pattaanaik T et al, $2016(6 \%) .^{[19,25,26]}$

Antenatal sonography is developed few decades back; however it continues to lag behind a complete fetal autopsy in accurately diagnosing the cause of fetal death. $\left[{ }^{27]}\right.$ Only few studies have shown comparison of antenatal ultrasonographic findings \& autopsy findings. In the present study, autopsy diagnosis confirmed ultrasonographic findings in 54 cases $(94.74 \%$ ), among these in 27 cases $(47.37 \%)$ it provided additional information, whereas primary diagnosis given by ultrasonography was changed in 3 cases $(5.26 \%)$. The findings in the present study are similar to those of Sankar and Phadake et al. ${ }^{[23,28]}$

The most common system involved was musculoskeletal followed by central nervous system. Similar finding was noted by Potekar et al, 2013, ${ }^{[22]}$ Tomatir et al $2009,{ }^{[8]}$ and Andola US et al 2012.[23]

Various combinations of systems involved in malformations were noted. This could be attributed to same embryological period of development of different systems.In this study the 13/57 (22.80\%) cases showed multiple malformations occurring in single fetus or neonate. Variety of syndromes have been identified in the study like Down's syndrome, Potter's syndrome etc. Few rare syndromes were encountered like Limb body wall complex /Body stalk anomaly refers to a rare complicated polymalformative fetal malformation syndrome of uncertain etiology.

Antenatal detection of such malformations is important, in planning the management, and achieving better outcomes, and to reduce recurrence.

\section{Conclusion}

Perinatal autopsy is useful in detecting and confirming congenital malformations in fetuses and neonates. Identification and classification of the visceral congenital malformations can be achieved with good autopsy 
technique. Bad obstetrics history, low birth weight for gestational age and prematurity, male sex are the most frequently observed factors associated with development of congenital malformations.

Despite advances in imaging such as antenatal ultrasonography and serology, perinatal autopsy is superior and continues to play an important role in diagnosing congenital malformations. The findings of autopsy are not only of theoretical importance but also of practical significance to clinicians in the form of estimating the risk of recurrence and in genetic counseling.

\section{References}

1. McCandless SE, Brunger JW, Cassidy SB. The burden of genetic disease on inpatient care in a children's hospital. The American Journal of Human Genetics2004; 74(1):121-127.

2. MacDorman MF, Atkinson JO. Infant mortality statistics from the 1997 period linked birth/infant death data set. National Vital Statistics Reports, 1999; 47(23):1-23.

3. Rosano A, Botto LD, Botting B, Mastroiacovo P. Infant mortality and congenital anomalies from1950 to 1994: an international perspective. Journal of Epidemiology \& Community Health2000; 54(9): 660-666.

4. EUROCAT Working Group, Surveillance of congenital anomalies in Europe 1980-1999, EUROCAT Report 8,Universty of Ulster, Belfast, UK, 2002.

5. Fida NM, al-Aama J, Nichols W, Alqahtani M. A prospective study of congenital malformations among live born neonates at a University Hospital in Western Saudi Arabia. Saudi Medical Journal 2007; 28(9): 1367-1373.

6. Bower C, Callaghan A, Quick J. Report of the Birth Defects Registry of Western Australia, Tech. Rep. no. 15, King Edward Memorial Hospital, Women and Newborn Health Service, 2010.

7. Abdi-Rad I, Khoshkalam M, Farrokh-Islamlou H R. The prevalence at birth of overt congenital anomalies in Urmia, Northwestern Iran. Archives of Iranian Medicine 2008; 11(2):148-151.

8. Tomatir AG, Demirhan H, Sorkun HC, K"oksal A, Ozerdem F, ilengir NC. Major congenital anomalies: a five-year retrospective regional study in Turkey. Genetics and Molecular Research 2009; 8(1);19-27.

9. Taksande A, Vilhekar K, Chaturvedi P, Jain M. Congenital malformations at birth in Central India: a rural medical college hospital based data. Indian Journal of Human Genetics 2010; 16(3)159-163.

10. Agha MM, Williams JI, Marrett L, To T, Dodds L. Determinants of survival in children with congenital abnormalities: a long-term population-based cohort study. Birth Defects Research A: Clinical and Molecular Teratology2006; 76(1): 46-54.

11. Taboo ZA. A prevalence and risk factors for congenital anomalies in Mosul City. Iraqui Postgraduate Medical Journal 2012; 22(2):140-146.

12. Shamim A, Chohan N, Sobia Q. Pattern of congenital malformations and their neonatal outcome. Journal of Surgery Pakistan.2010;15: 34-37.

13. al-Mendalawi MD. Pattern of neonatal and postneonatal deaths over a decade (1995-2004) at a military hospital in Saudi Arabia. Saudi Medical Journal2008; 29(10)1518-1521.

14. Penchaszadeh VB. Delivery of genetic services in developing countries. In: M. J. Khoury, W. Burke, and E. Thompson eds. Genetics and Public Health in the 21st Century. New York, USA: Oxford University Press2000: 301-327.

15. Long G, Spring A. A comparative study of routine versus selective fetal anomaly ultrasound scanning. American College of obstetricians and Gynecologists 1998; 5: 6-10.

16. Potter EL. Pathology of the fetus and infants. 1st ed, New York: Mosby Co;1997.

17. World Health Organisation. The ICD-10 version 2010, Classification of Congenital malformations, deformations and Chromosomal abnormalities. Geneva, 1994 (http:// apps.who.int/classifications/icd10/browse/2010/en\#/XVII) accessed on 08/05/2016.

18. Burton JL, Underwood JCE. Necropsy practice after the 'Organ retention Scandal'. Requests, performance, and tissue retention. J. ClinPathol 2003; 56: 537-541.

19. Pattanaik T, Samal S, Jena T. Study of Congenital Anomalies in a Tertiary Care Hospital. Indian Journal of Neonatal Medicine and Research 2016; 4(3):1-4.

20. Parmar A, Rathod SP, Patel SV, Patel SM. A Study of Congenital Anomalies In Newborn. NJIRM 2010;1(1): 13-17.

21. Hakverdi S, Guzelmansur I, Gungoren A, Toprak S, Yaldiz M, Hakverdi A U. Evaluation of Fetal Autopsy Findings in the Hatay Region: 274 Cases. Turk PatolojiDerg 2012;28(2):154-161

22. Potekar RM, JavalgiPA, Yelikar B R. Autopsy study to determine fetal anomaly: a retrospective Cohort study. Int J Pharm Bio Sci 2014; 5 (3): 64 - 69.

23. Andola US, Anita AM, Ahuja M, Andola SK. Congenital malformations in perinatal autopsies- A study of 100 cases. JCDR 2012;6(10):1726-1730.

24. Subhashini R, Uma N, Neeraja. Incidence and Evaluation of Congenital Malformations in Victoria Govt. Hospital Visakhapatnam, Andhra Pradesh. JMSCR 2015; 3(2):4022-4036.

25. Madi SA, Al-Naggar RL, Al-Awadi SA, Bastaki LA. Profile of major congenital malformations in neonates in Al-Jahra region of Kuwait. East Mediterr Health J 2005; 11:700-06. 
26. Ordonez MP, Nazer J, Aguila A, Cifuentes L. Congenital malformations and chronic diseases of the mother. Latin American collaborative study of congenital malformations 1971-1999. Rev Med Chil 2003; 131:404-11.
27. Nayak SR, Garg N. Determination of antepartum fetal death. J ObstetGynecol India 2010; 60: 494-97.

28. Sankar VH, Phadke SR. Clinical utility of fetal autopsy and com $\neg$ parison with prenatal ultrasound findings. Journal of Perinatology2006; 26: 224-29.

*Corresponding author:

Dr Pradnya Pandurang Kale, 286/C, SadashivPeth, Pune 411030, Maharashtra, India.

Phone: +91 9890281018

Email: pradnyaj.patho@gmail.com

Date of Submission : 09.01.2017

Date of Acceptance : 06.06.2017

Financial or other Competing Interests: None.

Date of Publication : 31.08.2017 